\title{
A Study to Explore the Effects of Sound Vibrations on Consciousness
}

\author{
Meera Raghu \\ Independent Researcher, New Zealand
}

\begin{abstract}
Sound is a form of energy produced by vibrations caused by movement of particles. Sound can travel through solids (such as metal, wood, membranes), liquids (water) and gases (air). The sound vibrations that reach our ear are produced by the movement of particles in the air surrounding the source of sound. The movement or vibration of particles produces waves of sound. Sound waves are longitudinal and travel in the direction of propagation of vibrations. The pitch of sound is related directly to its frequency, which is given by the number of vibrations or cycles per second. The higher the pitch of sound, the higher is its frequency, and the lower the pitch, the lower is its frequency. Human ear can hear sounds of frequencies ranging from $20-20,000$ cycles per second (or $\mathrm{Hertz}-\mathrm{Hz}$ ). Sound waves can be visually seen and studied using 'Chladni' plates, which was devised and experimented by Ernst Chladni, a famous physicist with a passion for sound/music. In this experiment the source of sound is connected via a wave driver to the Chladni metal plate with fine sand strewn on it. The sound vibrations cause the plate to vibrate at the same frequency, which causes movement of the sand particles to form patterns of the sound generated. The visual patterns comprise of nodes or regions where the sand particles accumulate, and antinodes or regions where the sand particles drift away from. Each frequency of sound causes a particular pattern to be formed on the plate. The study of wave phenomena is also called 'Cymatics' (Raghu, 2016). Sound vibrations can come in contact physically through the body and have an effect on our consciousness at the mental, emotional and spiritual levels. Sounds that are musical can be categorized as consonant sounds that are pleasant, and dissonant sounds that are unpleasant or not so pleasant. Musical sounds are comprised of notes in increasing or decreasing order of pitch (frequency). The interval between notes can give rise to consonance and dissonance. Example, an interval of an octave -a range of seven notes - is said to be consonant, whereas an interval between adjacent notes can be dissonant. These are studied by experimenting with musical notes and intervals, their visual patterns and their effect on consciousness. While consonant intervals can
\end{abstract}

cause happiness, joy, courage or calmness, dissonant intervals can cause tension, anger, fear or sadness, thereby affecting the emotional aspect of consciousness.

Keywords Consciousness, Sound, Vibration, Music, Emotion, Chladni, Pattern, Energy

\section{Introduction}

Sound is everywhere. There is perpetual movement and action in the world around us, and this produces a variety of sounds, such as those coming from Nature, from animals, those generated by humans in the form of speech or music, those that are generated by vehicles, machines, gadgets that are used for comfort, leisure and convenience. What is interesting or important about Sound? Sound is an integral part of our lives. Whether we like it or not, the vibrations of these sounds reach us, not only through the hearing sense, but also by coming into contact with the physical body. The sound vibrations can affect us either positively or negatively, entering into our being, via the physical, mental and emotional realms, thereby affecting our consciousness as a whole. Therefore, while it is important, it would also be interesting, to know more about the nature of sound, how it affects us, and in what way we can harness it positively and try to reduce its negative impact on us.

Sounds that we hear can be either pleasant - such as music, or unpleasant - such as noise. Music is an important aspect of sound. We listen to music of on the radio and television, and via live or recorded concerts of musicians, for entertainment. We are exposed to a variety of music, classical music, folk music or film music, and Western or Eastern music. Whatever the type, music is comprised of what are known as notes, which are tones of sounds of certain quality that help create pleasantness in the listener. Music has a positive influence in humans, plants and animals (Arka, 2013, p. 31). It would help to have a basic understanding of the theory of sound vibrations, the fundamental concepts of music, as music comprises sound 
vibrations.

\section{Nature of Sound Vibrations}

The sounds we hear are characterized by sound vibrations and are propagated as sound waves. Sounds waves require a medium, such as solid, liquid or gas, through which the sound vibrations can be transmitted. The sound waves coming from a sound source, such as the human voice or musical instrument, are typically transmitted as sound vibrations in the surrounding air, and communicated to the destination, such as the human ear. Sound waves are mechanical in nature, because the vibrations are transmitted mechanically to the surrounding air (or any medium), through a series of compressions and rarefactions of the particles in the air (or any medium). Sound waves are longitudinal waves, meaning that the direction of vibrations of air particles (or of any medium) is in the same direction as the propagation of the waves.
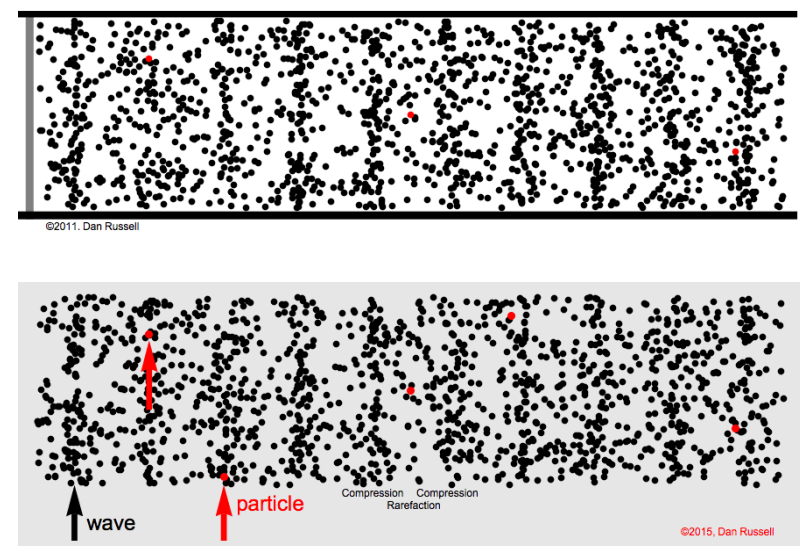

Figure 1. Sound waves in particles of Air (Image/Animation Credit: Courtesy of Dr. Dan Russell, Grad. Prog. Acoustics, Penn State (Russell, D., n.d.)

Traveling wave

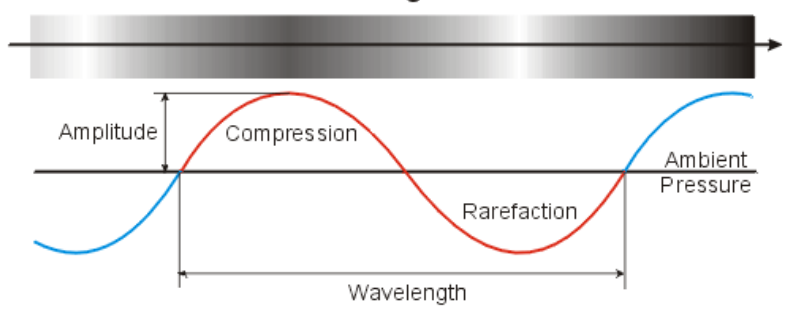

Figure 2. Sound waves (Image Credit: https://method-behind-the-music.com/mechanics/physics/)

Sound Vibrations are measured in terms of Frequency / Pitch, Wavelength, Amplitude:

- Frequency is the number of vibrations per second, also known as cycles per second (Hertz-Hz);
- Wavelength is the length of a single wave (vibration); In other words, the wavelength is the spacing of a wave; the distance from the high-point of one wave to the next high-point of the wave; that is, between the point of one crest of the wave and the next crest of the wave; or between the point of one trough of the wave and the next trough of the wave. The wavelength of the wave is highlighted in red in Figure 2 above.

- Amplitude is the intensity or loudness (volume) of sound;

- Pitch indicates if a particular sound is of higher or lower frequency; it is commonly used in music to describe whether a note is of high pitch or low pitch. The frequency is a precise scientific unit of measurement; while pitch, although defined by its frequency, also has a subjective component that takes into account the relative placement of the frequency within the context of an established tuning system and in relation to other frequencies.

\section{Musical Concepts}

Let us look at some of the common terms used in music:

Musical tone is a steady periodic sound. A musical tone is characterized by its pitch, duration, loudness and timbre. A pure tone is a simple tone with simple wave form, and a complex tone is a combination of two or more pure tones.

Musical Note is a complex form of musical tone and is characterized by its pitch, duration, loudness, and timbre. In addition, it is not periodic and includes vibrato, transients or graceful embellishments applied to it. In Indian music, a note is called Swara.

Timbre is the quality of the musical sound produced. It is that quality by which a musical sound or note can be identified with reference to which source it comes from, for example, whether it is voice, or musical instruments such as violin, drum, veena, or flute, and so on.

Pitch is a perceptive property a musical sound or note can be identified with reference to its frequency. Pitch of a note is directly related to its frequency - high pitch refers to high frequency, low pitch refers to low frequency. Pitch does not refer to the absolute frequency value, but indicates its position, whether high or low, in a given frequency range. Pitch in music is used to arrange musical notes in a particular order.

Scale is a range of musical notes ordered by a fundamental frequency or pitch. A scale may have notes in increasing order of pitch, which is called ascending scale; or it may have notes in decreasing order of pitch, which is called descending scale. Scales in Western and Indian music are shown in Table 1 below. 
Table 1. The 7 Notes of a Scale in Western and Indian music

\begin{tabular}{|c|c|c|c|c|c|c|c|}
\hline \multirow{2}{*}{ Western music } & C & D & E & F & G & A & B \\
& do & re & me & fa & so & la & te \\
\hline \multirow{2}{*}{ Indian music } & S & R & G & M & P & D & N \\
& sa & ri & ga & ma & pa & da \\
\hline
\end{tabular}

Early studies in Indian music have derived musical scales by modal shift of tonic, which is the scale obtained by shifting the fundamental or base note. The earliest of scales with a minimum of three notes was used to chant from the sacred scriptures such as the Vedas and was known as Sāma gāna. Thereafter the pentatonic scales (five notes), hexatonic (six notes) and heptatonic scales (7 notes) were discovered by early music scholars (Sambamurthy, P., n.d.). Pentatonic scales are very widely used in the music of many countries, as these provide aesthetic appeal and have a positive effect on the listener.

Interval in music is the difference in the pitches of two notes. The smallest of the intervals is called a semitone and smaller than that are called microtones, in Western music. In Indian music, semitones and even smaller intervals such as quarter-tones and microtones are used.

Chromatic Scale is a musical scale comprising 12 notes of different pitches, where (1) each adjacent note may be at an equal interval of semitone from the other (equal tempered scale in Western music), or (2) the interval between adjacent notes are ratios of small whole numbers - for example, $3 / 2,4 / 3$ and so on (Just intonation as in Indian music).

\section{Musical Notes of Western and Indian Music}

The range of notes in a chromatic scale is typically 12 in number. The seven notes in Western have slight variations in pitch and contribute to the 12 notes, whereas in Indian music, only five notes have slight variations in pitch, two notes remain unchanged, contributing to the 12 notes. A musical note in Indian Music is called 'Swara' in Sanskrit. Notes/Swaras in Western and Indian music are shown in Table 2.

Table 2. The 12 notes of a Scale in Western and Indian music

\begin{tabular}{|c|c|c|c|c|c|c|c|c|c|c|c|c|}
\hline Western music notes & $\mathrm{C}$ & $\begin{array}{c}\mathrm{C \#} \\
\mathrm{Db}\end{array}$ & $\mathrm{D}$ & $\begin{array}{c}\mathrm{D} \# \\
\mathrm{~Eb}\end{array}$ & $\mathrm{E}$ & $\mathrm{F}$ & $\begin{array}{c}\mathrm{F} \# \\
\mathrm{~Gb}\end{array}$ & $\mathrm{G}$ & $\begin{array}{c}\mathrm{G} \# \\
\mathrm{Ab}\end{array}$ & $\mathrm{A}$ & $\begin{array}{c}\mathrm{A} \# \\
\mathrm{Bb}\end{array}$ & $\mathrm{B}$ \\
\hline Indian music Swaras & $\mathrm{S}$ & $\mathrm{R}_{1}$ & $\begin{array}{c}\mathrm{R}_{2} \\
\mathrm{G}_{1}\end{array}$ & $\begin{array}{c}\mathrm{R}_{3} \\
\mathrm{G}_{2}\end{array}$ & $\mathrm{G}_{3}$ & $\mathrm{M}_{1}$ & $\mathrm{M}_{2}$ & $\mathrm{P}$ & $\mathrm{D}_{1}$ & $\begin{array}{c}\mathrm{D}_{2} \\
\mathrm{~N}_{1}\end{array}$ & $\begin{array}{c}\mathrm{D}_{3} \\
\mathrm{~N}_{2}\end{array}$ & $\mathrm{~N}_{3}$ \\
\hline
\end{tabular}

The frequency or frequencies at which an object tends to vibrate with when hit, struck, plucked, strummed or somehow disturbed is known as the natural frequency of the object. If the amplitudes of the vibrations are large enough and if natural frequency is within the human frequency range, then the vibrating object will produce sound waves that are audible. Octave in music is the interval between a note of a particular pitch (or frequency) and another note which is double or half the pitch (or frequency). Depending on whether the pitch is double or half, it is called higher octave or lower octave, respectively.

\section{Natural Frequency}

The frequency or frequencies at which an object tends to vibrate when hit, struck, plucked, strummed or disturbed is known as the natural frequency of the object. If the amplitudes of the vibrations are large enough and if natural frequency is within the human frequency range, then the vibrating object will produce sound waves that are audible (Natural Frequency, n.d.).

\section{Standing Waves}

Sound vibration inside a tube forms a standing wave. A standing wave is the result of the wave reflecting off the end of the tube (whether closed or open) and interfering with itself.

\section{Nodes and Antinodes}

In a sound wave, the areas of highest vibration are called antinodes and areas of least vibration are called nodes.

\section{Fundamental, Overtones and Harmonics}

When sound is produced in an instrument by blowing it, only the waves that will are generated by the air-column in the tube resonate. The longest wave that can be generated in the tube is called the fundamental, while other waves that are generated are called overtones. Overtones are multiples of the fundamental frequency. Overtones are other frequencies besides the fundamental frequency that exists in musical instruments. Instruments of different shapes and actions produce different overtones. The overtones combine to form the characteristic sound of the instrument. The natural frequencies of an object or a musical instrument are referred to as the harmonics of the object or musical instrument. 


\section{Standing wave in an open pipe}

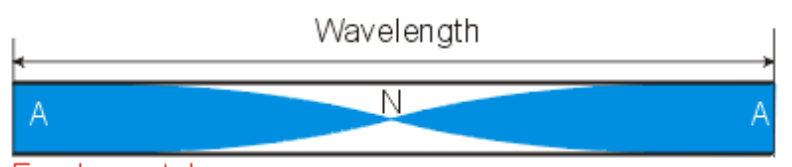

Fundamental wave

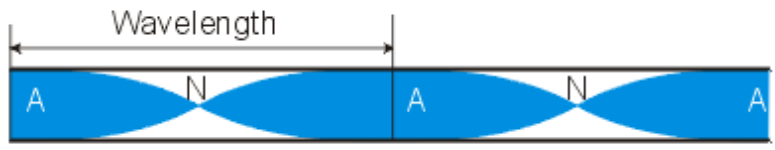

A harmonic wave

Figure 3. Standing waves (Image Credit: https://method-behind-the-music.com/mechanics/physics/)

\section{Beats}

When two (or more) sounds are produced having a frequency difference of less than about 20 or $30 \mathrm{~Hz}$, you will hear "beats." The frequency of the beats will be at the difference frequency. If the frequency difference is larger than about 20 or $30 \mathrm{~Hz}$, a tone is usually perceived rather than distinct beats.

\section{Resonance}

A musical instrument can be forced into vibrating at one of its harmonics (with one of its standing wave patterns) if another interconnected object pushes it with one of those frequencies. This is known as resonance - when one object vibrating at the same natural frequency of a second object forces that second object into vibrational motion. The word resonance comes from Latin and means to "resound" - to sound out together with a loud sound. Resonance is a common phenomenon of sound production in musical instruments.

\section{Entrainment}

This involves changing the natural vibrational frequencies of an object and replacing them with different vibrational frequencies of another object, thereby actively changing the vibrations of one object to that of another object. Entrainment is considered as an active method, whereas resonance is considered as a passive method. (Healing Sounds, n.d.)

\section{Ragas of Indian Music}

Ragas form the basic feature of Indian music. A raga has a distinct musical entity, has a separate aesthetic form and can be recognized by a trained ear. A raga consists of musical notes of a particular scale within an octave. The number of notes that a raga may have, can range from a minimum of four notes to seven notes. One of the oldest ragas is Mohana, which is a pentatonic raga.

\section{Sruti}

A sruti is a note of minute pitch which can be identified by a trained ear. It is a musical interval with the smallest audible difference of pitch and is a fraction of a semitone. The values of srutis can be expressed in terms of vibration per second.

\section{Consonance and Dissonance in Musical Intervals}

Consonance is that quality of a musical interval, which has a pleasant or harmonious effect on the listener. The fundamental note and its octave bear a ratio of 1:2, which means that the frequency of a higher octave note to the fundamental is double that of the fundamental note itself. Such an interval is called unison and has a pleasant effect on the listener. In Indian Music, Consonance is known as 'Samvaaditva' in Sanskrit and produces harmony. The notes are called Consonant notes or Samvaadi swaras and are said to be consonant to each other. In the same way, when a fundamental note and its perfect fifth note, which bear a ratio of $3 / 2$, provide a pleasant experience to the listener. It constitutes the first landmark in the evolution of the tone system.

Dissonance is that quality of a musical interval, which does not have a pleasant or harmonious effect on the listener. The intervals between adjacent notes mostly produce dissonance. Dissonance is known as 'Vivaaditva' in Sanskrit and produces disharmony. The notes are called Dissonant notes or Vivaadi swaras and are said to be dissonant to each other.

Some musical intervals are neither consonant nor dissonant, because they neither have pleasant or unpleasant effect on the listener. Such intervals are called Supportive intervals, also known as Anuvaaditva in Sanskrit. The notes in the interval are Anuvaadi swaras.

These form the basis of Indian music in creating a pleasant effect and providing harmony.

The effect of musical intervals on health is also significant in Western Music.

One of the reasons why listening to music is so healing for us, is due to the power of musical intervals. A musical interval is created when one note is played with another note. The interval can be created by playing two notes together, or one after the other. When two notes are played together the interval has a stronger effect on us. The frequencies of the two notes of the interval create a mathematical ratio that affects the body in different ways. When we listen to all the intervals in the musical scale it is profoundly healing for our body and our mind. Pythagoras discovered that the ratios of the musical intervals were found in nature, the planets and constellations. (Simon, H., n.d.)

The relation between musical intervals and emotions are shown in the Intervals Table. (Ref: Table 3 below). 
Table 3. Intervals and Emotions (Ch. 4, 4.4., Emotional Effects of Intervals. n.d.)

\begin{tabular}{|c|l|}
\hline $\begin{array}{c}\text { Interval or Interval } \\
\text { Type }\end{array}$ & \multicolumn{1}{|c|}{ Associated Emotions } \\
\hline Consonant intervals & $\begin{array}{l}\text { Pleasantness, generally positive emotional } \\
\text { valence; not as strong or active as dissonant } \\
\text { intervals }\end{array}$ \\
\hline Dissonant intervals & $\begin{array}{l}\text { Generally negative emotional valence, } \\
\text { strength, activity }\end{array}$ \\
\hline Major intervals & Brightness, strength \\
\hline Minor Intervals & Dullness, weakness \\
\hline Large intervals & Power \\
\hline Small intervals & Weakness \\
\hline Minor second & Melancholy, displeasure, anguish, darkness \\
\hline Major second & $\begin{array}{l}\text { Pleasurable longing, displeasure (neutral as a } \\
\text { passing tone; see Chapter 9) }\end{array}$ \\
\hline Minor third & Tragedy, sadness \\
\hline Major third & Joy, happiness, brightness \\
\hline Perfect fourth & $\begin{array}{l}\text { Buoyancy, pathos (neutral as a passing tone; } \\
\text { see Chapter 9) }\end{array}$ \\
\hline Mritone (diabolus in & $\begin{array}{l}\text { Violence, danger, tension, devilishness (of } \\
\text { course!) }\end{array}$ \\
\hline Musica) & Cheerfulness, stability \\
\hline Dominant seventh & Anguish, sadness \\
\hline Irresolution, displeasure, mournfulness \\
\hline Aseventh & Aspiration, displeasure, violent longing \\
\hline as a passing tone; see Chapter 9)
\end{tabular}

\section{Understanding Consciousness}

\section{Philosophical Perspective}

Consciousness is an abstract concept that has been the subject of study for scientists and philosophers for a number of years. Consciousness pervades everything throughout the universe. There is consciousness in every living entity as well as non-living entity. It is the aspect with which an entity perceives everything and itself in the universe. Whatever we see, hear, touch, taste, and feel, enters into our consciousness first through the senses and then as decoded information from the brain.

In one philosophical study, Consciousness is explained as follows.

"In human beings, consciousness manifests as awareness. This is also true of plants and animals, but their expressions of awareness are different from those of humans. For instance, plants show their awareness by responding to music with improved yields of fruits, flowers and crops. Humans also have this awareness in abundance. A person is said to be conscious when they can be aware of what they are sensing, including processes such as thinking, seeing, hearing, feeling and imagining. When a person is conscious, they experience their surroundings. Conscious awareness takes one to an even deeper level. It is not just a matter of raising awareness intellectually through knowledge. Here you raise your awareness emotionally and with the full involvement of your deeper mind prevailing in the heart region. In this process you gain positive energy, intuitive wisdom and a sense of direction. It is not logical but one can experience it mystically - an inner reality which has the potential to become an outside reality." (Arka, 2013, p. 31, 38-39)

Conscious Awareness is awareness with full involvement of the heart. The level of conscious awareness varies amongst the various entities; the non-living entities having conscious awareness at the very lowest level, or even at zero; whereas the living entities have conscious awareness varying ranging from lower to higher levels. Consciousness has many layers (Arka, 2013) as quoted below.

There are 6 Main Levels of Consciousness:

M (Mind) - Consciousness: Mind is the first level, which manifests on the surface of the cerebral region. As it becomes sharpened by the cultivation of learning, it evolves into a faculty called Intellect.

SM (Subliminal-Mind) - Consciousness: The second level, which is below the surface mind, is the subliminal or subconscious mind. We are unaware of its potential and capabilities, which may seem incredible to the surface mind. Many of your daily activities are governed by your subconscious mind.

$F$ (Feeling-Mind) - Consciousness: The third level is the feeling mind. This feeling-consciousness generally prevails in the heart area and can thus be called the Heart or Heart-Consciousness. It includes an emotional faculty called intuition. Almost all mothers have this faculty naturally available and readily accessible to help them understand the intense needs of their children and people they care about.

$H$ (Emotional-Heart) - Consciousness: The fourth level is the deeper heart, where you feel emotions with even greater intensity. This can be called the spiritual heart, or your inner consciousness. The presence of the surface mind is reduced, but the presence of the subliminal or subconscious mind is enhanced. It is formed by impressions gathered through all you have learned and experienced, along with the imprint of your personality.

HS (Heart-Soul) - Consciousness: The fifth level is between the deeper heart and the ultimate essential being (Soul). Here you experience inner-space, and the mystical Universe, where generally the laws of physics start reversing (for example, it is not time-bound and gives an experience of timelessness, and an experience of inner 
space, which is beyond physical space). This could lead you to experience many alternate realities and possibilities that give access to your own soul. Here you become more connected with Nature and the forces of the Universe.

PS (Pure-Self) - Consciousness: The sixth level is core consciousness. This is the very essence of your whole presence and of everything that you feel, think and do. It is addressed as the Soul or Self. It is the inner-most consciousness, the ultimate essential being.

The different levels of consciousness within can be experienced via the inner voyage of Intuitive Meditation, but much dedication is needed to explore one's Inner Self. (Arka, 2013, p. 36-38)

\section{Neuroscience Perspective}

In recent years, neuroscientists have been trying to find the true nature of consciousness, by means of the "Neural Correlates of Consciousness (NCC) - its goal is to find the difference between neural activity that produces consciousness and that which does not. It is defined loosely to start with as: the awake state in which we have experiences about which we can report at free will or request." (Lamme, n.d.).

Consciousness is also described as: "It is what vanishes every night when we fall into dreamless sleep and reappears when we wake up or when we dream. Thus, consciousness is synonymous with experience of shapes or sounds, thoughts or emotions, about the world or about the self. Consciousness depends on certain parts of the brain." (Tononi, G., 2012).

Another theory named Integrated Information Theory (IIT) of consciousness, proposed the axioms of IIT as "Intrinsic Existence: consciousness exists and each experience is actual; Composition: Consciousness is structured and each experience is composed of multiple phenomenological distinctions, elementary or higher-order; Information: consciousness is specific and each experience is the particular way it is; Integration: Consciousness is unified, each experience is irreducible to non-interdependent, disjoint subsets of phenomenal distinctions; Exclusion: Consciousness is definite, in content and spatio-temporal grain, each experience has the set of phenomenal distinctions it has, neither less nor more, and the experience flows at a particular speed, neither faster nor slower." (Tononi, G., 2015)

"The IIT strives to provide a theoretical approach to the precise quantification of the richness of experience for any conscious system. This requires calculating the maximal amount of integrated information in a system. IIT refers to this as the system's phi $(\Phi)$ value, which can be expressed numerically, at least in principle." (Fallon, F., n.d.).

A further explanation to understand Phi: "Phi or $\Phi$ is a measure of the system's 'integrated information'. In Consciousness, Koch equates phi to "synergy," the degree to which a system is "more than the sum of its parts." Phi can be a property of any entity, biological or non-biological.
Even a proton can possess phi, because a proton is an emergent phenomenon stemming from the interaction of its quarks.” (Hogan, J., 2015).

Neuroscientist Antonio Damasio's perspective of Consciousness: "What is consciousness? What is a conscious mind?

Consciousness is that which we lose when we fall into deep sleep without dreams or when we go under anesthesia, and it is what we regain when we recover from sleep or from anesthesia." (Damasio, A., 2011)

\section{Perception of Consciousness}

What is it exactly that we lose when we are in deep sleep or when we are under anesthesia?

The Mind: it is a flow of mental images - that can be sensory patterns, visual, tactile or auditory images - this flow of mental images is the mind.

The Self: there is something else other than what we experience. We are not passive exhibitors of visual, tactile or auditory images; we have 'selves'. So, we have a 'self' that is within the conscious mind.

A conscious mind is a mind with a self in it; A self introduces a subjective perspective in the mind; we are only fully conscious when self comes to mind. A portion of the brain stem actually makes brain maps of different aspects of our interior, different aspects of our body; they are exquisitely topographic, and exquisitely interconnected in a recursive pattern. It is out of this tight coupling between the brain stem and the body, that we generate this mapping of the body that provides the grounding for the Self, and that comes in the form of feelings, primordial feelings, by the way. So we get a picture of interconnectivity, in which we have the brain stem providing the grounding for the Self, in a very tight interconnection with the body; and we have the cerebral cortex providing the great spectacle of our minds with the profusion of images that are the contents of our minds, and that we normally pay most attention to as we should, because that's really the film that is rolling in our minds.

Antonio Damasio continues that: You cannot have a conscious mind if you don't have the interaction between cerebral cortex and brain stem; you cannot have a conscious mind if you don't have the interaction between the brain stem and the body. There are three levels of Self to consider: the proto self, the core self, and the autbiographical self. The autobiographical self is built on the basis of past memories and memories of the plans that we have made. It is the lived past and the anticipated future. The autobiographical self has prompted extended memory, reasoning, imagination, creativity, and language. (Damasio, A., 2011).

\section{Emotion and Consciousness}

According to Antonio Damasio:

The feeling of an emotion is a process that is distinct from having the emotion in the first place. So, in order to understand what a feeling is, we need to understand what 
an emotion is. An emotion is the execution of a very complex program of action; some actions that are actually movements - external - movement of our limbs hands/feet, expressions of face etc.), and internal - that happen in the heart or gut; and movements that are actually not muscular movements - but rather releases of molecules - say for example in the endocrine system - into the blood stream. In a broad sense, it is movement in action.

An Emotion consists of a very well-orchestrated set of alterations in the body that has, as a general purpose, making life more survivable, by taking care of a danger or taking care of an opportunity, or something in between.

A Feeling is actually the portrayal of what is going on in the organism when you are having an emotion. If you have just an emotion, you would not necessarily feel it. To feel an emotion, you need to represent in the brain in structures that are actually different from the structures which lead to the emotion - what is going on in the organism when you are having the emotion. So, you can define very simply, as the process of perceiving what is going on in the organism when you are in the throes of an emotion. And that is achieved by a collection of structures - some of which are in the brain stem, some of which are in the cerebral cortex, namely the insular cortex.

Emotion is a reaction to the world. Emotions are engaged when the states outside of our organism are fairly high in positive or negative directions. Emotion is in a way, a contribution to a sort of an auto-pilot. So, this is a level of response to the world, that is automated, and it is largely non-conscious. Then you take consciousness of it, and once you start feeling what is happening, and connecting the feeling to what you are perceiving, then you realize that there is the danger or opportunity. The entire process is then made conscious and enters the mind flow. Then the experiences of emotion also have a way of modelling what you are going to do next, because we have feelings which can actually stay in memory. Then we have a possibility of using feelings of certain emotions for future planning. It is a way of keeping alive, and also of constructing a view of the world, and making sure that the view is taken into consideration when planning future events. (Damasio, A., 2011)

\section{When Emotions Make Better Decisions}

We cannot always make decisions by logical reasoning alone. It is because the lift that comes from emotion. It is emotion that allows you to mark things as good, bad or indifferent, literally in the flesh. And it is that kind of emotional impetus that are lacking. We are constantly being swayed in what we do; what we remember from the previous situation is not the facts, not just the outcome that may be good or bad; we also remember whether or not what we felt was good or bad. When you are making decisions, and of course the options you make are going to produce good or bad outcome or something in-between, you do not only remember what the factual result is, but also what the emotional result is. That tandem of fact and associated emotion is critical, and of course, most of what we csntruct as wisdom over time, is actually a result of cultivating that knowledge about how our emotions behaved and what we learnt from them (Damasio, A., 2009).

\section{Physics / Mathematics Perspective}

According to physicist Max Tegmark:

"Consciousness is mathematical pattern : the way information feels when processed in a particular way.

How could something as complicated as consciousness possibly be explained by something as simple as particles? Because consciousness is a phenomena that has properties above and beyond the propereties of its particles. Physicists call such phenomena as Emergence phenomena." (Tegmark, M., 2014)

Tegmark states that the characteristic properties of ice, water and water vapour are different even though they are made of the exact same kind of water molecules. They are different due to the arrangement of particles of water molecules in them. Just as there are certain conditions under which various states of matter - such as steam, water, and ice - can arise, so too can various forms of consciousness, he argues. So it's not the particles that make a difference, it's the patterns into which they are arranged. Solids, liquids and gases are all emergence phenomena in that they have properties above and beyond those of their particles; they have properties that the particles don't have.

Similary, he thinks that: "consciousness too is an emergence phenomena. Because if one drifts off to sleep and consciousness goes away, one is still made of the same particles, the only thing is the pattern of arrangement of the particles.

\section{Properties of Consciousness}

How can a bunch of moving particles that are physical, possibly feel as non-physical as our consciousness? He thinks: Because consciousness doesn't only have properties above and beyond those of its parts, but also has properties that are independent of its parts, independent of its substrate, independent of the stuff that it is made of. There are also other phenomena in Physics that are also substrate independent in that sense - for example - waves these have properties like wavelength, frequency, speed and we can describe them with equations, even without knowing what kind of substance the waves are in. So these waves take a life of their own, above and beyond the substrate - for eg., the waves can cross a lake even though the individual water molecules are going around in tiny little circles.

More specifically consciousness is the way information feels when it has been processed in certain complex ways. So this means that it is substrate independent and it also means that it's only the structure of the information processing that matters not the structure of the matter that 
is doing the information processing. Consciousness is simply the way information feels when it is being processed in certain complex ways - by particles moving around in very special patterns; it is the patterns that really matter. (Tegmark, M., 2014)

\section{Physics Perspective - Superstring Theory}

According to Physicist Dr Brian Greene:

Superstring Theory is the theory that tries to answer the question: what are the basic fundamental indivisible uncuttable constituents making up everything in the world around us.

The idea is like this: we imagine we look at a familiar object - candle and a holder. Imagine that we want to figure out what it is made of. So, we go on a journey deep inside the object and examine the constituents. Deep inside we all know if you go sufficiently far down, we have the atoms; beyond the atoms, they have electron that swarm around the central nucleus that has neutrons and protons. Even the neutrons and protons have smaller particles inside of them known as Quarks. That is where conventional ideas stop. Here is the new idea of String Theory. Deep inside any of these particles there is something else - the something else is this dancing filament of energy - it looks like a vibrating string - that's where the idea of String Theory comes from. And just like the vibrating strings of a cello or musical instrument can vibrate in different patterns, these can also vibrate in different patterns - they don't produce different musical notes - rather they produce the different particles making up the world around us. This is what the ultra-microscopic landscape of the universe looks like. It is built up of a huge number of these little tiny filaments of vibrating energy, vibrating in different frequencies, the different frequencies produce the different particles, the different particles are responsible for all the richness in the world around us. And there you see unification - because matter particles, electrons and quarks, radiation particles, photons, gravitons, are all built up from one entity - so matter and the forces of nature are all put together under the rule-... of vibrating strings and that's what we mean by a Unified Theory.

But there is the catch: when you study the mathematics of String Theory - you will find that it doesn't work in a universe that just had three dimensions of space - nor 4, 5, or 6 - ... finally if you can study the equations you will find that it works only in a universe that has 10 dimensions of space and 1 dimension of time. It leads us right back to this idea of Kalutza and Kline that our world when appropriately described has more dimensions than the ones that we see - extra dimensions.

According to Newton: Absolute space - provided an arena, a stage.

According to Einstein: Space and time can warp and curve - and that's what gravity is.

According to String Theory: Gravity, Quantum Mechanics, Electromagnetism, all together in one package, only if the universe has more dimensions than the ones that we see. (Greene, B., 2005)

\section{Spiritual Perspective}

Imagine a spirit consciousness, floating in the vast nothingness or void, without the physical body or mind, and without anything around, just by itself. Spirit decides to expand its consciousness all around itself without moving. It creates a sphere around itself. This is the first circle created. It has an awareness of what is around itself in 360 degrees. Then the spirit-consciousness moves to the very edge of the sphere and again expands itself the same extent as before and creates another sphere, repeats what it did the first time. This gives rise to the second circle, and the resulting pattern is known as the vesica piscis.

The spirit continues flawlessly along the first sphere moving one radius away from the previous circle and expanding into a sphere and so on. This sphere will have its circumference passing through the centre of the first sphere. It continues to do this around the first sphere creating about six spheres around it. This is the beginning and it keeps continuing further and further creating more spheres around the newly created spheres.

Each time a new sphere is formed it gives rise to more information coming out of it. The first complete pattern or image that comes out of this is called the Seed of life or the Genesis pattern.

From the Seed of life pattern - emerges knowledge about mathematical proportions such as the right-angled triangle, angles, and knowledge about light etc. [See Figures 4 and 5 below].

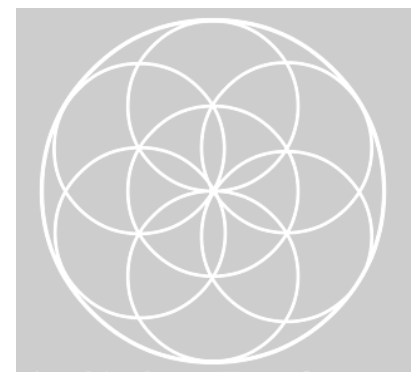

Figure 4. Seed of life
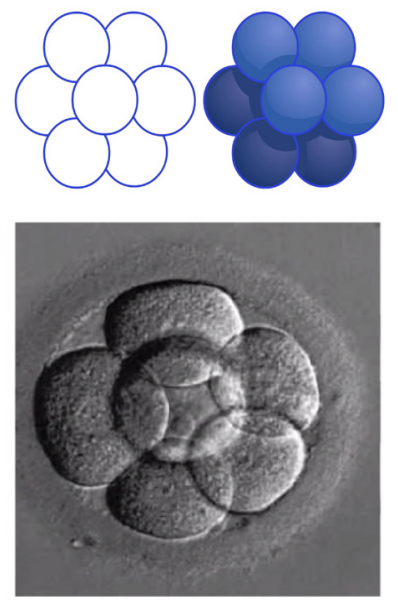

Figure 5. Egg of life (Views in 2d, 3d, real-life) 
The second image which is the egg of life is formed during the second vortex motion. Upon its completion it creates a three-dimensional shape, egg of life. The pattern continued to form the flower of life and continued further gives the fruit of life. Although this may be beyond any religious beliefs and thoughts, it seems to form the basis of many of the schools of thought that talk about creation (Melchizedek, D., n.d.; Spirit Science, n.d.).

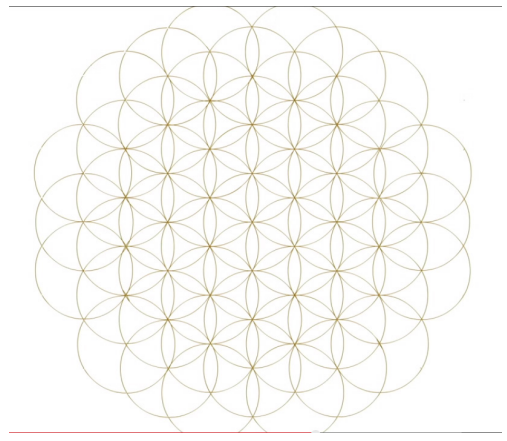

Figure 6. Flower of life

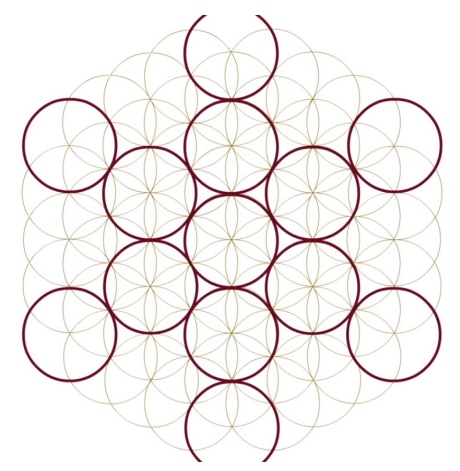

Figure 7. Fruit of life from Flower of life

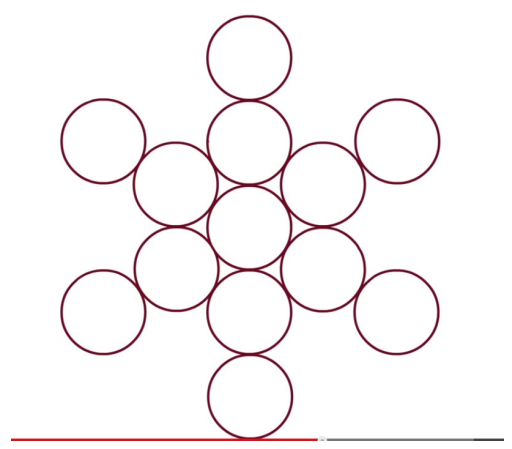

Figure 8. Fruit of life

This pattern with 13 circles is one of the most sacred forms of existence. This is called the Fruit of Life. From this fruit of life pattern, details of creation came into being and from which the fabric of the details of reality were created. It is one of the most important information systems in the universe, one of the basic creation patterns of consciousness in existence.

Everything in the universe follows a certain pattern, geometry or mathematical order that originated as the basis of creation. All the information whether tangible or non-tangible is said to have originated from this pattern of creation is known as the flower of life. All branches of knowledge, such as music, languages, science, and so on, are said to have originated from the flower of life, which has been found in many places around the world including India. (Melchizedek, D., n.d.; Spirit Science, n.d.).

\section{Effect of Consciousness on Water}

The works of Masaru Emoto, a Japanese author and researcher, have highlighted that human consciousness has an effect on the molecular structure of water. The result was that he always observed beautiful crystals after giving good words, playing good music, and showing, playing, or offering pure prayer to water. On the other hand, he observed disfigured crystals in the opposite situation. Emoto published several volumes of a work entitled Messages from Water, which contain photographs of ice crystals and their accompanying experiments. (Emoto, M., n.d.)

\section{Methodology}

Research and experimental studies on consciousness, emotions and feelings have shown that even though we are represented externally by the physical body, internally deep within us we are primarily made up of energies and patterns of vibration. This may also be understood from the perspective that the physical body consists of millions of cells of different kinds, which are in turn composed of molecules, atoms, sub-atomic particles such as quarks and even smaller particles, and finally in the form of patterns of energy that vibrate like strings (Greene, B., 2005).

As sound is composed of mechanical vibrations and is close to the physical, it is interesting to see how sound vibrations affect us. Musical sounds or notes are very closely related to emotions and feelings, each pattern or set of notes corresponding to a particular set of emotions, positive or negative. Consonant notes and intervals are said to produce positive emotions like joy, happiness, courage, enthusiasm, peace, and so on, whereas dissonant notes and intervals are said to produce negative emotions like anger, sadness, fear, and so on. The principle behind this research: when sound vibrations of consonant notes and intervals that produce positive emotions are applied externally to a human listener, then by the principle of entrainment, the emotional energies within the listener would also begin to vibrate in harmony with those sound vibrations applied externally. This in turn would help bring positive emotions and enhance positive energies within the body. (Sambamurthy, P., n.d.; Brown, R., Williams, L., etal, n.d.; Hagman, F., 2010; Willimek, D. \& B., 2013).

Scientists and acoustics engineers have carried out studies and experiments on sound vibrations since many years. One of the interesting experiments that caught attention was that of Ernst Chladni, a German physicist and 
musician, who conducted experiments with vibrating plates and sound patterns. He devised techniques to study the patterns of vibrations on mechanical surfaces, metal plates of different shapes. Chladni used a metal plate on the surface of which sand was sprinkled. When the plate was stroked on the edge with a violin bow, characteristic geometric patterns could be produced, depending on the location of the bow on the edge of the plate, and the physical dimensions of the plate. The patterns are formed by nodes/antinodes, representing points of zero/non-zero amplitudes. The patterns of vibration were revealed through the use of sand, which settles into the nodal lines producing strikingly remarkable shapes. The plates came to be known as 'Chladni Plates' and the patterns were called 'Chladni Figures'. These provided a way to visualize the effects of vibrations on mechanical surfaces. The famous pioneers who are known for their successful experimental work in the field of Cymatics are Robert Hooke, Ernst Chladni and Hans Jenny who gave the name Cymatics to this field of study. (Raghu, 2016)

\section{Experiment Using Chladni Plates}

The equipment used and the experimental setup for generating Chladni patterns are shown in Figure 9 and Figure 10 respectively.

Equipment comprises the following:

- Two metal Chladni plates - Circular and Square (24x24) cm

- Mechanical wave driver

- $\quad$ Signal generator $(0-800 \mathrm{~Hz})$

- Audio Amplifier

- Microphone, Connecting cables, Fine sand

The signal generator is connected to the wave driver. The Chladni plate (square or circular) is fitted at its centre on the spindle of the wave driver, to be able to vibrate freely upon excitation. The fine sand particles are sprinkled on the metal plate. The desired frequency is set on the signal source and the volume gradually increased, to find the vibration 'Chladni' patterns being formed on the plate by the movement of the sand towards the regions of the nodes and forming the respective patterns (see the images in Tables 4, 5 \& 6).

The Chladni patterns were produced with the signal generator as source for standard musical pitches of higher and lower octaves. The patterns were also generated and observed for the consonant notes in a Major Pentatonic Scale (known as Raga Mohana in Carnatic Music).

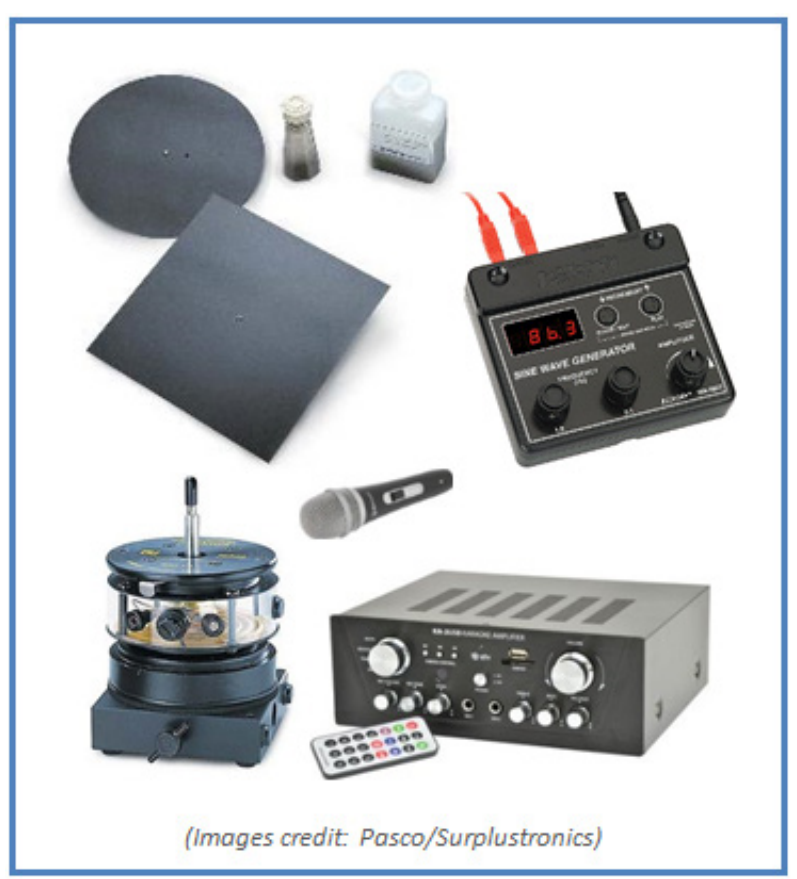

Figure 9. Equipment used

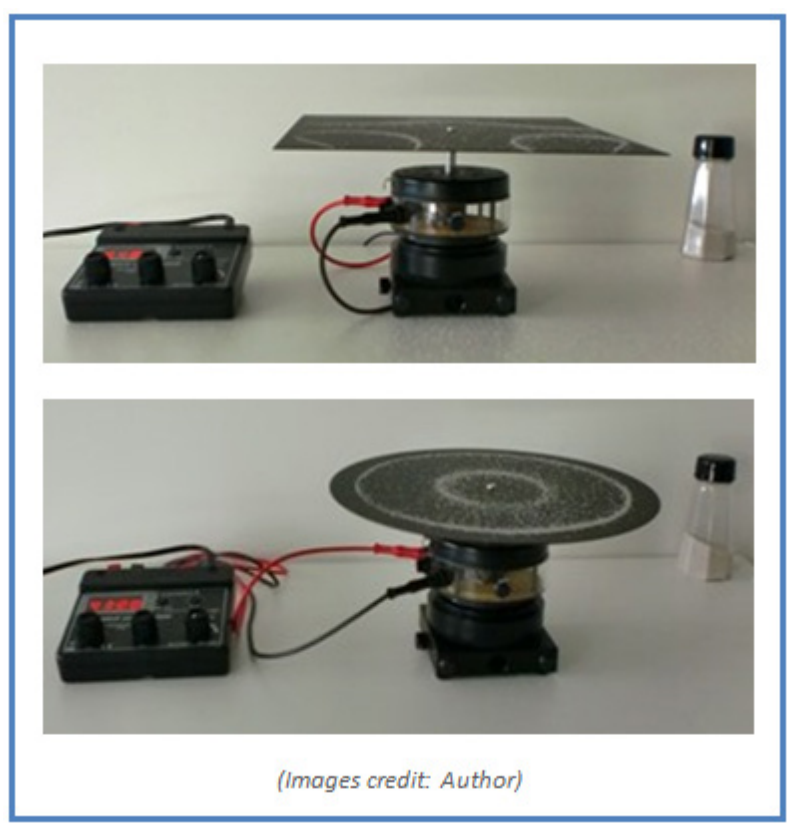

Figure 10. Experimental setup 


\section{Experiment 1}

The Chladni patterns were observed using square plates for frequency $440 \mathrm{~Hz}$ (middle note A) and lower/higher octaves (consonant notes) (See Table 4). The patterns are dependent on the dimensions of the plate, and it may be noted that these are kept constant and not varied while conducting the experiments.

Table 4. Chladni Patterns with Square plates (Signal Generator source)

\begin{tabular}{|c|c|c|c|}
\hline $\begin{array}{c}261.6 \mathrm{~Hz} \\
\text { (Middle C) }\end{array}$ & $\begin{array}{c}440 \mathrm{~Hz} \\
\text { (Middle A) }\end{array}$ & $\begin{array}{c}220 \mathrm{~Hz} \\
\text { (Lower octave of A) }\end{array}$ \\
\hline (Lower octave of A)
\end{tabular}

\section{Experiment 2}

The Chladni patterns were observed using square plates for male voice and female voice as well. (see Table 5). It may be noted that the male and female voices are an octave apart in frequency; therefore, they have a consonant interval between them.

Table 5. Chladni Patterns with Square plates (Voice source)

\begin{tabular}{|c|c|}
\hline Male voice & Female voice \\
\hline Frequency range $\sim(108-110) \mathrm{Hz}$ & Frequency range $\sim(216-220) \mathrm{Hz}$ \\
\hline & \\
\hline
\end{tabular}

\section{Experiment 3}

The Major Pentatonic scale, i.e. a five-note scale, (also called Raga Mohana in Carnatic Music), which consists of consonant notes, was chosen for this experiment. The notes of this pentatonic scale were used to generate the Chladni patterns using the square plates (see Table 6). 
Table 6. Chladni Patterns for Major Pentatonic Scale

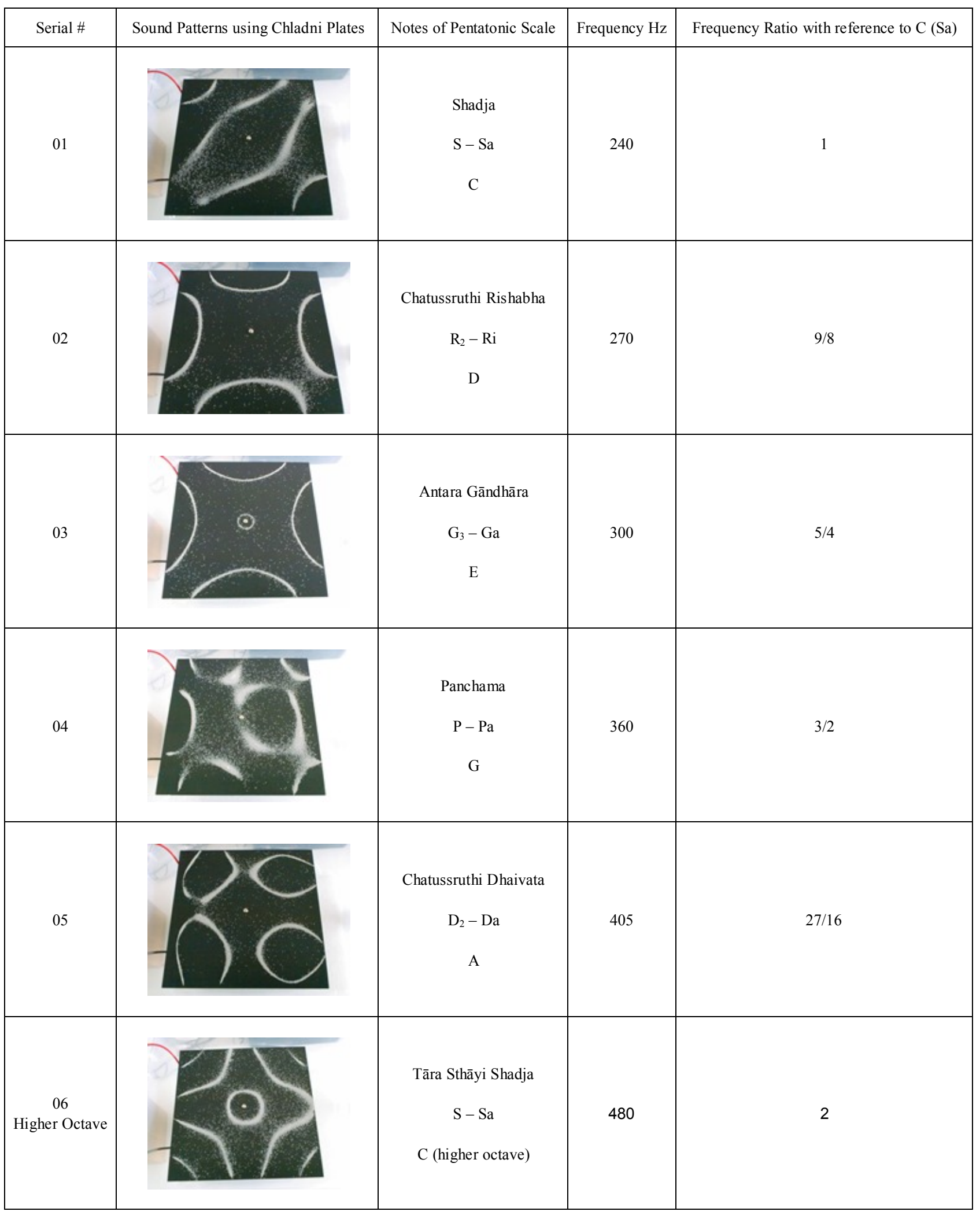


Studies by Hans Jenny (and followed by other scientists) show that when playing a toning sweep through a range of frequencies, there is a moment when chaos ensues when changing to another tone. He found that the chaos occurs when matter of any kind is rearranging itself into a new form based on the new frequency. Matter is designed to move away from chaos and into form and vice versa, a never-ending cycle that occurs on all levels continuously from our cells to our universe. This can be seen in patterns 3 (E-Ga), 4 (Pa-G) and 5 (Da-A), where the pattern for 4 (Pa-G) appears with less symmetry than those for $3(\mathrm{E}-\mathrm{Ga})$ and 5 (Da-A). Hans Jenny through his study of cymatics also developed a theory that molecules inside each cell of our body can be positively affected by sound vibration. (Linton, R., 2008)

\section{Conclusions}

Clear geometric patterns were observed when the vibrations were harmonious and pleasant. When using the voice as source (for the same pitch), it showed that the patterns were similar to those observed for the lower octaves using the signal generator as source.

The consonant notes and intervals in the pentatonic scale produced clear patterns, and are indicative of the harmonious nature of vibrations. It may be noted that the harmonious consonant notes are utilized in the humming of sounds during.

Every living entity is made up of a set of patterns of vibrations. The cells of our body can be positively affected by sound vibration. The human body has key energy centres.

These are called Chakras or portals in the human energy field. Located along the central channel of the body from the base of the spine to the top of the head, they are conceived of as whirling, wheel-like vortices through which universal/cosmic energy flows into and out of a person. There are seven major chakras, plus many minor ones. Each chakra corresponds to specific glands, organs, and facets of your being. Energy flows through the chakra system in two ways. First, it flows up and down along the central channel, connecting the chakras. Second, it flows horizontally, in an exchange of energy with the cosmos. Chakras can become blocked or imbalanced. This has a significant impact on the entire energy system. (Hauser, N., n.d.)

Sound and Music have healing characteristics which can be used in the balancing of the chakras and regulating the flow of energy in the system. Each chakra is associated with a sound, corresponding to each note of the musical scale as in Table 7 below.

Table 7. Chakras and Musical Notes

\begin{tabular}{|c|c|c|c|c|}
\hline Number & Chakra & $\begin{array}{c}\text { Note / Solfa name } \\
\text { (Western music) }\end{array}$ & $\begin{array}{c}\text { Note/Solfa name } \\
\text { (Indian music) }\end{array}$ & Endocrine Gland \\
\hline 1 & Root (Mooladhara) & $\mathrm{C}(\mathrm{Do})$ & $\mathrm{S}(\mathrm{Sa})$ & Reproductive \\
\hline 2 & Sacral (Swadhishtana) & $\mathrm{D}(\mathrm{Re})$ & $\mathrm{R}(\mathrm{Ri})$ & Adrenal \\
\hline 3 & Solar Plexus (Manipura) & $\mathrm{E}(\mathrm{Me})$ & $\mathrm{G}(\mathrm{Ga})$ & Pancreas \\
\hline 4 & Heart (Anahata) & $\mathrm{F}(\mathrm{Fa})$ & $\mathrm{M}(\mathrm{Ma})$ & Thymus \\
\hline 5 & Throat (Vishuddha) & $\mathrm{G}(\mathrm{So})$ & $\mathrm{P}(\mathrm{Pa})$ & Thyroid \\
\hline 6 & Third Eye (Ajna) & $\mathrm{A}(\mathrm{La})$ & $\mathrm{Na})$ & Pituitary \\
\hline 7 & Crown (Sahasrara) & $\mathrm{B}(\mathrm{Te})$ & Pineal \\
\hline
\end{tabular}

The effective use of musical notes and musical intervals (including subtle intervals of microtones, less than a semitone) which produce harmonious sound vibrations can work via the chakras the energy system, the endocrine system, generating a healing effect from a subtle level through to the physical, mental and emotional levels. This paves the way for possibility of further research in this area of healing and therapy for improving our health and well-being.

\section{Acknowledgements}

Dedicated to:

\section{Srinivas Arka}

Philosopher, author, inspirational speaker, developer of human positive potential programmes and Founder of the Centre for Conscious Awareness (CCA) Registered Charities globally.

\section{Tina Lindhard}

Chair of the XLIII CICA, International University of Professional Studies (Hawaii, USA), Chair of Consciousness Research CICA, President CCA Spain.

With grateful acknowledgements and my sincere thanks for this great opportunity provided to me for presenting a research paper at the XLIII CICA Conference at Mysuru, India.

Extending my sincere thanks to the Chairs and Members of the Scientific and Organizing Committees of the XLIII CICA Conference at Mysuru, India. 


\section{REFERENCES}

Arka, S. (2013). Arka Dhyana Intuitive Meditation. An enlightening journey into your inner realms initiated by your breath, sound and touch. Middlesex, UK: Coppersun Books.

Sambamurthy, Prof. P. (1998-2002). South Indian Music - Books $I$, II, III, IV, V, VI. Chennai, India: The Indian Music Publishing House.

Russell, Dan. (n.d.). Retrieved from

http://www.acs.psu.edu/drussell/Demos/waves/wavemotion.html

Brown, Norman R., Williams, Rebecca L., et al., (n.d.). Estimating frequencies of Emotions and Actions. Canada: University of Alberta.

Hagman, Fredrik (2010). Emotional Response to Sound. (n.d.). Goteborg, Sweden: Dept. of Civil \& Environmental Engg., Division of Applied Acoustics, Chalmers University of Technology. Master's Thesis 2010:157.

Willimek, Daniela and Bernd (2013). Music and Emotions. Research on the Theory of Musical Equilibration. (Translated from the German by Russell, Laura.)

Raghu, Meera. (2016). KAAS-News. (Vol.2 No.2, pp. 8-12). Bangalore, India: Karnataka Association for the Advancement of Science, Bangalore University. Retrieved from http://learningforknowledge.com/images/sci/KAAS-News-2016 Feb-Vol.02-No.02.pdf

Natural Frequency. (n.d.). Retrieved from

http://www.physicsclassroom.com/class/sound/Lesson-4/Natural -Frequency

Chapter 4: How Scales and Intervals Really Work? 4.4 Emotional Effects of Intervals. (n.d.). Retrieved from https://www.howmusicreallyworks.com/Pages_Chapter_4/4_4.h tml

Lamme, A.F. Victor. Can neuroscience reveal the true nature of consciousness? (n.d.). The Netherlands: Cognitive Neuroscience Group. University of Amsterdam.

Tononi, G. (2012). Integrated Information Theory of Consciousness: an updated account. Madison, WI, USA: Department of Psychiatry, University of Wisconsin. Archives Italiennes de Biologie, 150: 290-326.

Tononi, Giulio. (2015). Scholarpedia, 10(1): 4164.

Fallon, Francis. Integrated Information Theory of Consciousness. (n.d.). USA. Internet Encyclopedia of Philosophy IEP, St. John's University.

Hogan, John. (1 Dec 2015). Can Integrated Information Theory explain Consciousness? USA: Scientific American.

Damasio, Antonio. (19 Dec 2011). The quest to understand consciousness. TED talk: Retrieved from https://www.youtube.c om/watch?v=LMrzdk_YnYY.

Damasio, Antonio. (11 Aug 2009). When Emotions Make Better Decisions. Fora TV: Retrieved from $\mathrm{https}: / /$ www.youtube.com/watch?v=1wup_K2WN0I.

Tegmark, Max. (2014). Consciousness is mathematical pattern. Cambridge: TED talk: Retrieved from https://www.youtube.com $/$ watch? $\mathrm{v}=\mathrm{GzC}$ VlFRISIM.

Greene, Brian. (2005). Ted talk: Retrieved from https://www.ted.com/talks/brian_greene_on_string_theory.

Melchizedek, Drunvalo. Flower of Life and Merkaba. (n.d.). Retrieved from http://www.drunvalo.org/

Spirit Science. (n.d.). Retrieved from http://thespiritscience.net/flower-of-life/

Emoto, Masaru. (n.d.). Retrieved from http://www.masaru-emoto.net/english/water-crystal.html

Healing Sounds. (n.d.). Retrieved from https://www.healingsoun ds.com/sonic-entrainment/

Linton, Rachael. (2008). Sound Vision - Patterns of Vibration in Sound. Wellington, New Zealand: Symbols and the Body, Master of Design Thesis, Institute of Communication Design, Massey University.

Hauser, Nancy. (n.d.). What are Chakras? A Quick Overview. Retrieved fromhttps://www.the-energy-healing-site.com/chakratones.html 